\title{
Open arthrolysis for elbow stiffness increases carrying angle but has no impact on functional recovery
}

\author{
Dapeng Fan', Wei Wang ${ }^{1}$, Kevin A. Hildebrand ${ }^{2}$ and Cun-yi Fan ${ }^{1 *}$
}

\begin{abstract}
Background: With the exception of normal anatomic changes in the medial collateral ligament and radial head, other factors related to carrying angle changes have not been systematically studied. We reviewed patients who underwent open arthrolysis of the elbow, and evaluated if open arthrolysis could change carrying angle. We then identified factors associated with carrying angle changes.

Methods: Fifty patients with a minimum of 24 months of follow-up after open arthrolysis were evaluated retrospectively. Preoperative and postoperative carrying angles were compared.

Results: The carrying angles of 36 elbows in 36 patients were unchanged after surgery (Group A), while the carrying angles of 14 elbows in 14 patients increased postoperatively (Group B). In Group A, mean postoperative extension and flexion were $7^{\circ}$ (range $0-24^{\circ}$ ) and $125^{\circ}$ (range $10-135^{\circ}$ ) respectively, while mean postoperative pronation and supination were $60^{\circ}$ (range $50-80^{\circ}$ ) and $65^{\circ}$ (range $30-85^{\circ}$ ), respectively. In Group B, mean postoperative extension and flexion were $25^{\circ}\left(\right.$ range $0-40^{\circ}$ ) and $128^{\circ}$ (range $60-138^{\circ}$ ), while mean postoperative pronation and supination were $65^{\circ}$ (range $45-85^{\circ}$ ) and $60^{\circ}$ (range $45-75^{\circ}$ ), respectively. No significant difference in range of motion and Mayo Elbow Performance Score was observed between the two groups.
\end{abstract}

Conclusions: During open arthrolysis, humeral trochlea debridement and techniques for improving forearm rotation could increase carrying angle. However, this had no impact on elbow functional recovery.

Keywords: Carrying angle, Open arthrolysis, Elbow stiffness, Humeral trochlea, Forearm rotation

Abbreviations: $\mathrm{HO}$, Heterotopic ossification; LCL, Lateral collateral ligament; MCL, Medial collateral ligament; MEPS, Mayo elbow performance score; ROM, Range of motion

\section{Background}

Carrying angle, first described by Braune and Kyrklund $[1,2]$, is the angle between the shafts of the humerus and extended ulna. This angle is usually $0-25^{\circ}$ or, $155-180^{\circ}$ supplementary angle [3]. Physiologically, carrying angle is greater in females than in males, and is greater in the non-dominant arm [2, 4]. Zampagni [5] and Morry [6] both reported that carrying angle varied with elbow flexion in a linear fashion. Pathologically, increased and decreased carrying angle is defined as cubitus valgus and

\footnotetext{
* Correspondence: fancunyi888@163.com; fancunyi800@163.com 'Department of Orthopaedics, Shanghai Jiao Tong University Affiliated Sixth People's Hospital, 600 Yishan Road, Shanghai, People's Republic of China200233

Full list of author information is available at the end of the article
}

cubitus varus, respectively. Carrying angle changes are mostly documented after supracondylar fractures of the humerus in children [7]. Otherwise, carrying angle changes are rarely mentioned.

Elbow stiffness is a common complication of elbow trauma [8, 9]. Up to $12 \%$ of all posttraumatic elbows require surgical intervention [10]. Open arthrolysis of the elbow has recently gained widespread acceptance for treating elbow stiffness $[8,11-15]$. However, in our experience few patients' carrying angles are changed after open arthrolysis. Previous biomechanical studies using cadaver elbows have found that the medial collateral ligament (MCL) is the primary constraint to lateral instability caused by cubitus varus and valgus, while the radial head is a secondary constraint $[16,17]$. However, other 
contributors to carrying angle changes have not been systematically studied. Here we reviewed our past 50 elbow open arthrolysis cases, aiming to evaluate if open arthrolysis can change carrying angle, and the overall impact of this change on operative outcomes. By analyzing the characteristic operative manipulation of each patient and summarizing the reasons for changing their carrying angle, we hope to improve our operative outcomes.

\section{Methods}

The Shanghai Sixth People's Hospital's review board approved this retrospective study and written informed consent for each patient was required.

\section{Subjects}

We performed a retrospective review of 50 patients (22 men, 28 women) with elbow stiffness from August 2010 to June 2014. Ethical approval was given by the medical ethics committee of our institution, and an informed consent approved by the Institutional Review Board was signed by each patient. All patients were available for an average of 24 months after surgery (range 18 to 42 months). Inclusion criteria included: (1) skeletally mature; (2) post-traumatic elbow stiffness with a range of motion (ROM) no greater than $60^{\circ}$; and (3) elbows that underwent open arthrolysis and were fixed with a hinged external fixator. Exclusion criteria were: (1) associated congenital cubitus varus/valgus; and (2) associated malunion or nonunion requiring interposition arthroplasty or total joint arthroplasty. All operations were performed by the same senior surgeon. Carrying angle was measured using standard anteroposterior X-rays taken by two experienced radiologists. We measured carrying angle according to methods previously described by Papaziogas [3]: (a) elbow joint axis, defined as a line through the center of the humeral condyle and trochlea; (b) the brachial leg of the carrying angle, corresponding with a line through the width of the humerus (approximately $15 \mathrm{~cm}$ from the joint axis) and the middle of the joint axis; and (c) the ulnar leg, corresponding with a line through the middle of the joint axis and the middle of the soft tissues of the forearm (approximately $15 \mathrm{~cm}$ from the joint axis). In view of the variation in carrying angle throughout elbow flexion, we analyzed elbow radiographs at maximum extension and recorded the maximum elbow extension angles.

Postoperative elbow radiographs were taken in the same position. We first ensured that the postoperative extension angle of elbow was consistent with the preoperative extension angle measured in the lateral projection. We then measured the carrying angle on an anteroposterior photo of elbow in the same position. Patients with an unchanged carrying angle were defined as Group A, and patients with carrying angles that changed were defined as Group B.
Surgical techniques and postoperative management

Surgical procedures were performed according to previously described techniques [11-13]. During a medial approach to the elbow, the ulnar nerve was routinely identified, released from its tunnel, and transposed. The olecranon fossa or fossa coronoidea would be exposed for anterior or posterior joint clearing and joint capsule release. If needed, the hypertrophic capsule was excised. From the lateral approach, contracture releases of the annular ligament and humeroradial joint were required to treat forearm rotation defects. Some radial heads were removed to improve forearm rotation. Blunt dissection of the triceps, heterotopic ossification ( $\mathrm{HO})$ excision, and resection of the posterior and transverse bundles of the medial collateral ligament were performed to further improve range of motion. Suture anchors were used to repair the dissected collateral ligaments and a hinged external fixator was applied. Detailed operative manipulation of each patient was recorded. Highlights of the manipulation include capitulum, radial head, humeral trochlea, coronoid process and coronoid fossa plasties, debridement of the humeroradial joint, humeroulnar joint, olecranon, olecranon fossa and proximal ulnar radial joints, release of the biceps, brachialis, brachioradialis, pronator teres, flexor carpi radialis, anterior capsule, triceps muscle, anconeus muscle, posterior capsule, MCL and lateral collateral ligament (LCL), excision of the radial head and anterior and posterior osteophytes, reconstruction of the MCL and LCL, and radial head replacement.

Patients began active and passive flexion-extension and pronation-supination exercises on the first day after surgery under our supervision. Exercises were generally performed for half an hour, three times a day during the first week. The length of each session was gradually extended to $1 \mathrm{~h}$. Celecoxib (25 mg) was taken three times a day for 4 weeks to prevent $\mathrm{HO}$ [18]. The hinged external fixator would be removed 6 weeks after surgery. The valgus stress and lateral pivot shift tests were performed for posterolateral rotary instability [19].

\section{Data analysis}

All statistical analysis was performed using SPSS software (version 13.0; SPSS, Chicago, IL, USA). Chi-square tests were used to compare differences between Group A and Group B in operative characteristics. Statistical significance was defined as $p<0.05$. A $t$-test was used to analyze operative effects such as elbow range of motion (ROM) and Mayo Elbow Performance Score (MEPS) preoperatively and postoperatively. Significance was set as $p<0.05$.

\section{Results}

The carrying angles of 36 elbows in 36 patients were unchanged (Group A), while the carrying angles of 14 elbows in 14 patients increased (Group B). Significant 
between-group differences were observed in the following: plasty of the radial head $(p=0.014)$ and humeral trochlea $(p=0.029)$, proximal ulnar radial joint debridement $(p=0.031)$, biceps release $(p=0.044)$, and radial head excision $(p=0.018)$ (Table 1$)$. Open arthrolysis with a unilateral hinged external fixator increased carrying angle, radial head and humeral trochlea plasties, proximal radioulnar joint debridement, biceps release and radial head excision were high risk factors.

Table 2 lists preoperative and postoperative ROM and MEPS measurements. In Group A, the mean postoperative extension and flexion were $7^{\circ}$ (range, $0-24^{\circ}$ ) and $125^{\circ}$ (range $10-135^{\circ}$ ), respectively. The mean postoperative pronation and supination were $60^{\circ}$ (range $50-80^{\circ}$ ) and $65^{\circ}$ (range $30-85^{\circ}$ ), respectively. In Group B, the mean postoperative extension and flexion were $25^{\circ}$ (range $0-40^{\circ}$ ) and $128^{\circ}$ (range $60-138^{\circ}$ ), respectively. Mean postoperative

Table 1 Comparison of operative manipulation performed for Group A and Group B

\begin{tabular}{|c|c|c|c|c|}
\hline \multicolumn{2}{|c|}{ operative manipulation } & \multirow{2}{*}{$\begin{array}{l}\text { Group A } \\
n=36\end{array}$} & \multirow{2}{*}{$\begin{array}{l}\text { Group B } \\
n=14 \\
0\end{array}$} & \multirow{2}{*}{$\begin{array}{c}P \text { value } \\
0.304\end{array}$} \\
\hline Plasty & capitellum & & & \\
\hline & radial head & 2 & 5 & 0.014 \\
\hline & humeral trochlea & 6 & 7 & 0.029 \\
\hline & coronoid process & 2 & 1 & 1.000 \\
\hline & coronoid fossa & 5 & 0 & 0.304 \\
\hline & olecranon & 26 & 6 & 0.099 \\
\hline & olecranon fossa & 27 & 7 & 0.105 \\
\hline \multirow[t]{3}{*}{ Cleaning } & humeroradial joint & 3 & 2 & 0.611 \\
\hline & humeroulnar joint & 10 & 6 & 0.330 \\
\hline & proximal ulnar radial joints & 5 & 7 & 0.031 \\
\hline \multirow[t]{11}{*}{ Debridement } & biceps & 2 & 4 & 0.044 \\
\hline & brachialis, & 2 & 0 & 1.000 \\
\hline & brachioradialis & 2 & 0 & 1.000 \\
\hline & pronator teres & 3 & 3 & 0.331 \\
\hline & flexor carpi radialis & 1 & 0 & 1.000 \\
\hline & triceps muscle & 26 & 6 & 0.099 \\
\hline & anconeusm muscle & 7 & 2 & 1.000 \\
\hline & anterior capsule & 19 & 3 & 0.061 \\
\hline & posterior capsule & 16 & 3 & 0.197 \\
\hline & medial collateral ligament & 15 & 5 & 0.758 \\
\hline & lateral collateral ligament & 20 & 7 & 0.761 \\
\hline \multirow[t]{3}{*}{ Excision } & radial head & 1 & 4 & 0.018 \\
\hline & anterior osteophyte & 13 & 3 & 0.501 \\
\hline & posterior osteophyte & 15 & 3 & 0.211 \\
\hline \multirow[t]{2}{*}{ Reconstruction } & medial collateral ligament & 10 & 5 & 0.733 \\
\hline & lateral collateral ligament & 16 & 3 & 0.197 \\
\hline \multicolumn{2}{|c|}{ Radial head replacement } & 1 & 3 & 0.061 \\
\hline
\end{tabular}

Table 2 Preoperative and postoperative ROM and MEPS

\begin{tabular}{lllll}
\hline Mesurement & & Group A & Group B & $P$ value \\
\hline $\begin{array}{llll}\text { Preoperative ROM, } \\
\text { mean (range), }\end{array}$ & Extension & $23(0-75)$ & $15(5-55)$ & .213 \\
& Flexion & 83 & 90 & .745 \\
& Pronation & $43(25-120)$ & $(70-110)$ & \\
& Supination & $45(10-75)$ & $38(20-85)$ & .525 \\
& & $39-65)$ & .145 \\
Postoperative ROM, & Extension & $7(0-24)$ & $25(0-40)$ & .523 \\
mean (range), & Flexion & 125 & 128 & .243 \\
& & $(110-135)$ & $(60-138)$ & \\
& Pronation & $60(55-80)$ & $65(45-85)$ & .121 \\
MEPS, mean (range), & Preoperative & $59(40-70)$ & $51(45-70)$ & .172 \\
& Postoperative & $91(80-95)$ & $88(75-100)$ & .453
\end{tabular}

MEPS Mayo Elbow Performance Score, ROM range of motion. No significant difference was found regarding preoperative and postoperative ROM and MEPS between the 2 groups. $(P>0.05)$

pronation and supination were $65^{\circ}$ (range $45-85^{\circ}$ ) and $60^{\circ}$ (range $45-75^{\circ}$ ), respectively. No significant differences in ROM and MEPS were observed between the two groups.

HO was observed in two patients: one from Group A and another from Group B. Little finger numbness caused by ulnar nerve dysfunction occurred in three patients: two from Group A and one from Group B. There was no elbow instability diagnosed in either group. No significant differences in postoperative complications were observed between the two groups.

\section{Discussion}

Open arthrolysis with a unilateral hinged external fixator has been commonly used to treat posttraumatic elbow stiffness [20, 21]. To our knowledge, no prior work has evaluated the influence of an open arthrolysis on carrying angle. We found that while open arthrolysis for elbow stiffness could increase carrying angle, it did not affect ultimate functional recovery.

The formation and change of the carrying angle is mainly dependent on the distal humerus and proximal ulna [5, 22]. Any factors that can influence the static structure of the humeroulnar joint can change carrying angle. A static carrying angle not only relies on the integrity of the distal humerus and proximal ulna, but also depends on the surrounding protecting structures $[6,17,23,24]$. Heim [25] proposed the concept of elbow structure stability loops, which notes that elbow stability relies on four columns: lateral (capitulum, radial head and lateral collateral ligament), anterior (coronoid process, brachialis and anterior capsule), medial (coronoid process, medial collateral ligament and medial epicondyle of humerus) and posterior (olecranon fossa, musculus triceps brachii and posterior capsule). It can be concluded that both bony alignment and soft tissue structures such as ligaments and 
muscles can influence carrying angle. To avoid cubitus valgus and cubitus varus, which may be caused by joint laxity, special attention should be paid to maintaining the joint space and tension of the medial and lateral collateral ligaments when the incision is closed. More importantly, one or two suture anchors were used to repair the dissected collateral ligaments in cases of ligamentous laxity. Despite all this, risk factors that include radial head plasty, humeral trochlea plasty, debridement of the proximal radioulnar joint, biceps release and radial head excision still increased carrying angle in our study.

The humeroulnar joint, the main structure that creates the carrying angle, is composed of the olecranon and humeral trochlea. While the humeral trochlea was often debrided when $\mathrm{HO}$ and osteophytes developed, this may change the sliding track of the olecranon, thereby changing the carrying angle. Nakatani [26] and Zimmerman [27] both reported on patients with an isolated fracture of the humeral trochlea that showed an increased carrying angle with varus stress.

Radial head plasty, proximal radioulnar joint debridement and radial head excision are all performed to improve forearm rotation. As shown in Table 2, mean postoperative pronation and supination were improved in Group B. Carrying angle was measured at maximum supination, which suggests that carrying angle increased with increased supination ROM. This is consistent with work by Pomianowski et al. [28], who confirmed that valgus laxity of the elbow is forearm rotation-dependent. There are few existing articles on the potential effects of forearm rotation on elbow valgus alignment. Wening et al. [29] reviewed 39 patients with multi-fragmentary fractures of the radial head, or with radial neck fractures treated with radial head resection. They found that increased carrying angle was a characteristic complication of radial head excision. However, they did not provide justification for future work. Biceps release was a surprising contributor to carrying angle change, as it is often aimed at improving elbow flexion and extension. However, after reviewing the literature, we realized that the biceps supinates the forearm during contraction [30-32].

There was no association between increased carrying angle and elbow instability. This is because of the special attention paid to maintaining the tension of the medial and lateral collateral ligaments, and the fixation of the dissected ligaments with one or two rivets.

\section{Conclusion}

Operative manipulations such as humeroulnar joint debridement, radial head plasty, proximal radioulnar joint debridement, biceps release and radial head excision during an open arthrolysis for elbow stiffness can increase carrying angle. However, carrying angle changes do not affect elbow functional recovery.

\section{Availability of data and materials}

The data and materials contributing to this article may be made available upon request by sending an e-mail to the first author.

\section{Authors' contributions}

FDP conceived and designed this study, WW performed the literature searches. FDP extracted the data. FDP performed the statistical analyses, interpreted the data and drafted the manuscript. FCY and KAH revised the manuscript and acted as guarantor for the paper. The guarantors accept full responsibility for the conduct of the study, had access to the data, and controlled the decision to publish. All authors approved the final manuscript.

\section{Competing interests}

The authors declare that they have no conflict of interest.

\section{Consent for publication}

Not applicable.

\section{Ethics approval and consent to participate}

The Shanghai Sixth People's Hospital's review board approved this retrospective study and written informed consent for Dr. Fan to review the radiographs and clinical data of enrolled patients was signed by each patient.

\section{Author details}

'Department of Orthopaedics, Shanghai Jiao Tong University Affiliated Sixth People's Hospital, 600 Yishan Road, Shanghai, People's Republic of

China200233. ' McCaig Centre, Bone and Joint Institute, Faculty of Medicine, University of Calgary, Calgary, AB, Canada.

Received: 1 May 2016 Accepted: 5 August 2016

Published online: 09 September 2016

\section{References}

1. An KN, Hui FC, Morrey BF, Linscheid RL, Chao EY. Muscles across the elbow joint: a biomechanical analysis. J Biomech. 1981;14(10):659-69.

2. Yilmaz E, Karakurt L, Belhan O, Bulut M, Serin E, Avci M. Variation of carrying angle with age, sex, and special reference to side. Orthopedics. 2005;28(11):1360-3.

3. Paraskevas G, Papadopoulos A, Papaziogas B, Spanidou S, Argiriadou H, Gigis J. Study of the carrying angle of the human elbow joint in full extension: a morphometric analysis. Surg Radiol Anat. 2004;26(1):19-23.

4. Sharma K, Mansur DI, Khanal K, Haque MK. Variation of carrying angle with age, sex, height and special reference to side. Kathmandu Univ Med J (KUMJ). 2013;11(44):315-8.

5. Zampagni ML, Casino D, Zaffagnini S, Visani A, Marcacci M. Trend of the carrying angle during flexion-extension of the elbow joint: a pilot study. Orthopedics. 2008;31(1):76

6. Morrey BF, Chao EY. Passive motion of the elbow joint. J Bone Joint Surg Am. 1976;58(4):501-8.

7. Mehlman $\mathrm{CT}$, Crawford AH, Mcmillion TL, Roy DR. Operative treatment of supracondylar fractures of the humerus in children: the Cincinnati experience. Acta Orthop Belg. 1996;62 Suppl 1:41-50.

8. Everding NG, Maschke SD, Hoyen HA, Evans PJ. Prevention and treatment of elbow stiffness: a 5-year update. J Hand Surg [Am]. 2013;38(12): 2496-507. quiz 2507.

9. Bruno RJ, Lee ML, Strauch RJ, Rosenwasser MP. Posttraumatic elbow stiffness: evaluation and management. J Am Acad Orthop Surg. 2002;10(2):106-16.

10. Myden C, Hildebrand K. Elbow joint contracture after traumatic injury. J Shoulder Elbow Surg. 2011;20(1):39-44.

11. Ouyang Y, Liao Y, Liu Z, Fan C. Hinged external fixator and open surgery for severe elbow stiffness with distal humeral nonunion. Orthopedics. 2013;36(2):e186-92.

12. Wang W, Jiang SC, Liu S, Ruan HJ, Fan CY. Stability of severely stiff elbows after complete open release: treatment by ligament repair with suture anchors and hinged external fixator. J Shoulder Elbow Surg. 2014;23(10):1537-44

13. Ruan HJ, Liu S, Fan CY, Liu JJ. Open arthrolysis and hinged external fixation for posttraumatic ankylosed elbows. Arch Orthop Trauma Surg. 2013;133(2):179-85. 
14. Kodde IF, van Rijn J, van den Bekerom MP, Eygendaal D. Surgical treatment of post-traumatic elbow stiffness: a systematic review. J Shoulder Elbow Surg. 2013;22(4):574-80.

15. Valero Gonzalez FS, Gutierrez Sevilla GR, Aguilera Zepeda JM, Encalada-Diaz Ml, Ruiz-Suarez M. [Open surgical treatment in post-traumatic elbow stiffness]. Acta Ortop Mex. 2008;22(4):228-32.

16. Hotchkiss RN, Weiland AJ. Valgus stability of the elbow. J Orthop Res. 1987:5(3):372-7.

17. Morrey BF, Tanaka S, An KN. Valgus stability of the elbow a definition of primary and secondary constraints. Clin Orthop Relat Res. 1991;265:187-95.

18. Sun Y, Cai J, Li F, Liu S, Ruan H, Fan C. The efficacy of celecoxib in preventing heterotopic ossification recurrence after open arthrolysis for post-traumatic elbow stiffness in adults. J Shoulder Elbow Surg. 2015;24(11):1735-40.

19. Liu S, Liu JJ, Li XJ, Ruan HJ, Fan CY. Open arthrolysis and prosthetic replacement of the radial head for elbow stiffness associated with rotation limitation. J Shoulder Elbow Surg. 2013;22(2):275-9.

20. Ulmar B, Eschler A, Mittlmeier T. [Open arthrolysis of elbow stiffness]. Unfallchirurg. 2012;115(8):725-37. quiz 738.

21. Ayadi $D$, Etienne P, Burny F, Schuind F. Results of open arthrolysis for elbow stiffness. A series of 22 cases. Acta Orthop Belg. 2011;77(4):453-7.

22. An KN, Morrey BF, Chao EY. Carrying angle of the human elbow joint. J Orthop Res. 1984; 14):369-78.

23. Morrey BF, An KN. Articular and ligamentous contributions to the stability of the elbow joint. Am J Sports Med. 1983;11(5):315-9.

24. Morrey BF, An KN. Stability of the elbow: osseous constraints. J Shoulder Elbow Surg. 2005;14(1 Suppl S):174S-8.

25. Heim U. Kombinierte verletzungen von radius and ulnar in proximalen unteram segment. Hefte Unfallechir. 1994;241:61-79.

26. Abbassi N, Abdeljaouad N, Daoudi A, Yacoubi H. Isolated fracture of the humeral trochlea: a case report and review of the literature. J Med Case Rep. 2015;9:121

27. Zimmerman $\sqcup$, Jauregui JJ, Aarons CE. Isolated shear fracture of the humeral trochlea in an adolescent: a case report and literature review. J Pediatr Orthop B. 2015;24(5):412-7.

28. Pomianowski S, O'Driscoll SW, Neale PG, Park MJ, Morrey BF, An KN. The effect of forearm rotation on laxity and stability of the elbow. Clin Biomech (Bristol, Avon). 2001:16(5):401-7.

29. Wening JV, Wobig B, Jungbluth KH. Resection of the radius head in multiple and comminuted fractures. Clinical results and critical evaluation compared with the literature. Unfallchirurgie. 1993;19(3):175-82.

30. Naito A, Shimizu Y, Handa Y, Ichie M, Hoshimiya N. Functional anatomical studies of the elbow movements. I. Electromyographic (EMG) analysis. Okajimas Folia Anat Jpn. 1991;68(5):283-8.

31. Ibanez-Gimeno P, Galtes I, Jordana X, Malgosa A, Manyosa J. Biomechanics of forearm rotation: force and efficiency of pronator teres. PLoS One. 2014;9(2):e90319.

32. Basmajian JV, Latif A. Integrated actions and functions of the chief flexors of the elbow: a detailed electromyographic analysis. J Bone Joint Surg Am. 1957;39-A(5):1106-18.

\section{Submit your next manuscript to BioMed Central and we will help you at every step:}

- We accept pre-submission inquiries

- Our selector tool helps you to find the most relevant journal

- We provide round the clock customer support

- Convenient online submission

- Thorough peer review

- Inclusion in PubMed and all major indexing services

- Maximum visibility for your research

Submit your manuscript at www.biomedcentral.com/submit

) Biomed Central 